RESEÑ AS

\title{
La patrimonialización como herramienta de reparación de violaciones a los derechos humanos
}

\author{
Benjamín González Guzmán \\ Universidad de Chile
}

\begin{abstract}
g Pablo Seguel Gutiérrez, Derechos humanos y patrimonio: Historias/memorias de la represión (para)estatal en Chile. Santiago: Editorial del Servicio Nacional del Patrimonio Cultural, 2019, 271 páginas.
\end{abstract}

Bajo el rostro nuevo de cemento / Vive el mismo pueblo de hace tiempo / Esperando siguen los hambrientos / Más justicia, menos monumentos.

VUELVO, ILLAPU

La frase que sirve de epígrafe a esta recensión grafica el riesgo que reside en la patrimonialización como herramienta exclusiva para la satisfacción de las obligaciones de reparación y garantía de no repetición de las violaciones a los derechos humanos. Este peligro consiste en que, a través de la preeminencia de una estrategia de monumentalización como mecanismo de reparación y memoria, se sepulte bajo el mismo concreto de las esculturas y monumentos la posibilidad de obtener una verdadera justicia material respecto de estas violaciones. Utilizando la terminología propuesta por Seguel Gutiérrez, la preeminencia de políticas de memoria en desmedro de políticas de justicia. Cualquier lector de la obra reseñada debe tener siempre en consideración esta tensión, pues, al terminar el libro, podrá tener su propia opinión respecto de su desenlace en el contexto de la política transicional chilena.

Que el mapa no sea el territorio no quiere decir que el mapa no nos suministre información o algún tipo de acercamiento al objeto territorio. Esto pareciera tenerlo claro Pablo Seguel Gutiérrez, historiador y sociólogo, quien en un ejercicio integrador de distintas áreas de las ciencias sociales nos ofrece una aproximación didáctica y rigurosa de las tensiones que atraviesan el campo de la protección patrimonial en 
Chile, lo cual a su vez le sirve de excusa para construir un relato histórico coherente respecto de las violaciones a los derechos humanos durante la dictadura cívico-militar chilena y el consecuente proceso de reparación de estas violaciones.

El libro está estructurado en tres capítulos: el primero ofrece, en palabras del autor, «las coordenadas teórico-jurídicas que dotan de contenido la gestión patrimonial». Así, éste releva como fuente directa del auge del campo del patrimonio de los derechos humanos a la consolidación que ha tenido el derecho internacional de los derechos humanos durante las últimas décadas en Chile y el continente. Valga la prevención de señalar que el desarrollo de la patrimonialización no se enmarca sólo en el contexto de políticas reparatorias de las violaciones a los derechos humanos, sino también a la expansión de la propia concepción de derechos humanos al área que, no de manera pacífica, se ha conceptualizado como derechos económicos, sociales y culturales; más en específico, el derecho a la cultura y el patrimonio.

En el segundo capítulo, a partir de una reconstrucción histórica y correctamente documentada de las violaciones a los derechos humanos en dictadura, el autor propone una sistematización de la transición chilena hacia la democracia con la atención puesta en los procesos y mecanismos de establecimiento de la verdad (políticas del pasado) y mecanismos de reparación (políticas de la memoria). A partir de aquí, nos ofrece sin duda la mayor novedad de la investigación. Imbuido de la experiencia que le otorga su trabajo como encargado de memoriales y sitios de memoria de la Secretaria Técnica del Consejo de Monumentos Nacionales, y tomando fuentes históricas como el estudio de los programas de gobierno de los presidentes de la transición y las conclusiones ofrecidas por las comisiones creadas para el establecimiento de la verdad y la reparación (Valech, Rettig y Rettig II), entrega información relevante y correctamente expuesta para comprender los desafíos, tensiones y éxitos conseguidos en la transición hacia la democracia en lo que a patrimonialización de los sitios de memoria se refiere.

El lector no debe dejarse engañar por la especificidad del tema de la investigación (los procesos de patrimonialización de los sitios de tortura y prisión política en Chile como mecanismo de reparación a la sociedad y las víctimas), pues el autor nos entrega una investigación exhaustiva pero libre de ripio, en la cual a partir de la evolución y caracterización de este tema específico, ofrece un punto de vista desde el cual comprender y dotar de sentido un proceso social más amplio, como es la política represiva de la dictadura y la posterior política transicional propuesta desde el Estado para construir una verdad de lo ocurrido y proponer una reparación.

Enseguida, el capítulo tercero insiste en el método inductivo para ofrecer, a través del estudio de tres casos particulares de patrimonialización —Colonia Dignidad, el Complejo Forestal y Maderero Panguipulli (Cofomap) y el Museo Histórico Casa Parroquial de André Jarlán y Pierre Dubois—, una mirada más global de los procesos de memoria y reparación. 
Antes de estos tres capítulos se incluye, con fines contextuales, un capítulo introductorio que plantea los clivajes e interrogantes conceptuales que delinean el campo de la representación patrimonial, y un anexo metodológico que bien podría ser concebido como un manual práctico para quienes tengan interés en la gestión patrimonial.

La pertinencia de la publicación de este libro radica en que aparece en un momento histórico en que vuelven a arreciar las violaciones masivas de derechos humanos en el contexto de la crisis social de la primavera chilena del 2019. Así, se suman a la deuda pendiente de justicia y reparación respecto de las violaciones a los derechos humanos cometidas en dictadura, las mismas demandas respecto de las violaciones a los derechos humanos vividas durante las protestas ciudadanas del último trimestre del 2019.

Cuánto de estas experiencias pasadas nos sirve para enfrentar los desafíos presentes y futuros en esta materia, y cuánto tendrá que innovar el sistema de protección de los derechos humanos para abarcar experiencias de violaciones en contexto democráticos, son interrogantes que debemos resolver con urgencia y para las cuales este libro es sin duda un punto de partida obligatorio.

Lo anterior se comprende mejor si recordamos el hecho cierto de que el irrespeto por los derechos humanos no es un atributo exclusivo de las dictaduras, sino que es una mácula presente en la mayoría de las democracias, incluso en las más consolidadas. Evidentemente, el que se produzcan estas violaciones en un contexto democrático añade otros componentes al análisis, el cual requerirá adaptar las categorías jurídico-analíticas del pasado reciente a la realidad actual.

Por supuesto, el contexto democrático en el que se producen las actuales violaciones a los derechos humanos no implica necesariamente mejores posibilidades de justicia y reparación de estas conductas. La actual opacidad de las cifras e instituciones, el insuficiente control civil respecto del actuar de las policías, la falta de perspectiva de derechos humanos en algunas actuaciones judiciales y la carencia de una institucionalidad potente sobre la materia que permita, a través de herramientas efectivas, la prevención, castigo y reparación por violaciones de derechos humanos, son aspectos que colocan en una complicada tesitura al respeto de los derechos humanos y el castigo a sus violaciones.

Por otro lado, y ya exclusivamente en el ámbito de la patrimonialización de los derechos humanos - tema central del libro reseñado-, cabe destacar que pocas semanas después de la publicación del trabajo que aquí comentamos, la Comisión Interamericana de Derechos Humanos publicó el primer instrumento regional exclusivamente dedicado a tratar el tema de memoria y derechos humanos. ${ }^{1}$

1. Resolución 3/19, «Principios sobre políticas públicas de memoria en las Américas», aprobada en el marco de su $174 .^{\circ}$ período de sesiones celebrado en Quito, Ecuador, el 9 de noviembre de 2019. 
Este trabajo, en el cual se ofrece una guía destinada a las buenas prácticas estatales en materia de memoria y derechos humanos, surge a partir de una sistematización de los principios, reglas y directrices emanados del sistema interamericano de protección, los cuales por primera vez quedan explicitados en un instrumento que establece obligaciones para los Estados en la materia.

Dentro de los aspectos claves de este nuevo instrumento que complementa al corpus iuris de derechos humanos sobre el tema, podemos mencionar la explicitación de que «las políticas públicas de memoria se encuentran inscriptas en las obligaciones estatales de verdad, justicia, reparación y medidas de no repetición de las graves violaciones a los derechos humanos», además de reiterar que la verdad respecto de los hechos, circunstancias y autores de las violaciones a los derechos humanos, como ya correctamente recordaba Seguel Gutiérrez en su obra, es un derecho que le asiste tanto a las víctimas directas como al conjunto de la sociedad.

La pertinencia de este nuevo instrumento del derecho internacional de derecho humanos se observa en que ofrece un punto de partida cierto y vinculante para los Estados desde el cual se deberán elaborar y diseñar políticas públicas de memoria que pongan en el centro de sus objetivos el mandato de verdad, justicia y reparación de las víctimas y la sociedad.

En definitiva, el libro presentado es un correcto trabajo multidisciplinario, que a partir de la sociología, la historia y el derecho brinda los frutos de una rigurosa investigación que pone el acento en las prácticas represivas y reparatorias de los organismos estatales; ensaya una panorámica revisión de la literatura relativa a conceptos tan íntimamente ligados como verdad, justicia, memoria y reparación; entrega una valiosa reconstrucción historiográfica de los mecanismos utilizados por la dictadura cívico-militar chilena para dotar de un halo de legalidad sus crímenes de lesa humanidad, y ofrece herramientas metodológicas para la gestión patrimonial de sitios de memoria.

La segunda década del siglo XXI se ha inaugurado para Chile con dos de las crisis más severas de la historia reciente: la crisis social, respecto de la cual ya bastante se ha escrito, ${ }^{2}$ y la crisis sanitaria provocada por el covid-19, que mientras estas palabras son escritas, probablemente ya ha costado la vida de más de 5.000 chilenos. Estas coyunturas, sumadas a la anunciada crisis económica que ya se advierte, desafían todos los ámbitos del quehacer humano, dentro de los cuales sin duda está el derecho $\mathrm{y}$, más especialmente, los derechos humanos. ¿Qué rol tendrá la triada verdad, justicia y reparación durante los próximos años respecto de los traumáticos acontecimientos aquí mencionados? ¿Es la patrimonialización una herramienta adecuada para estos

2. Para una revisión panorámica de las causas y perspectivas del estallido social, véase Carlos Peña, Pensar el malestar (Santiago, Taurus, 2020), Alberto Mayol, Big bang. Estallido social 2019 (Santiagom Catalonia, 2019). 
nuevos desafíos? ¿Corremos el riesgo de repetir los errores de la transición chilena respecto de cierta preeminencia de la monumentalización de la justicia y reparación en desmedro de otras herramientas como el juicio y castigo de los responsables y el fortalecimiento de la institucionalidad de los derechos humanos en Chile? Son preguntas a las que urgentemente estamos llamados a responder, y respecto de las cuales el libro Derechos humanos y patrimonio ofrece una correcta aproximación.

\section{Sobre el autor}

Benjamín González Guzmán es licenciado en Ciencias Jurídicas y Sociales de la Universidad de Chile. Ayudante el Centro de Derechos Humanos de la misma universidad, donde hace labores como ayudante editorial del Anuario de Derechos Humanos. Ayudante del Centro de Derecho Ambiental de la misma casa de estudios. Su correo electrónico es b.gonzalezguzman@gmail.com. 
El Anuario de Derechos Humanos es una publicación semestral de referencia y consulta en materia de derechos humanos y campos afines. Busca ser un espacio de discusión de los temas centrales en el ámbito nacional e internacional sobre derechos humanos. Es publicado desde 2005 por el Centro de Derechos Humanos de la Facultad de Derecho de la Universidad de Chile.

\author{
EDITORA \\ Claudia Iriarte Rivas \\ ciriarter@derecho.uchile.cl \\ SITIO WEB \\ anuariocdh.uchile.cl \\ CORREO ELECTRÓNICO \\ anuario-cdh@derecho.uchile.cl \\ LICENCIA DE ESTE ARTÍCULO \\ Creative Commons Atribución Compartir Igual 4.o Internacional
}

\author{
\% \\ La edición de textos, el diseño editorial \\ y la conversión a formatos electrónicos de este artículo \\ estuvieron a cargo de Tipográfica \\ (www.tipografica.io)
}

